\title{
The aesthetics of theory selection and the logics of art
}

\author{
Abstract: \\ Philosophers of science discuss whether theory selection depends on aesthetic judgments or criteria, \\ and whether these putatively aesthetic features are genuinely extra-epistemic. As examples, \\ judgments involving criteria such as simplicity and symmetry are often cited. However, other theory \\ selection criteria, such as fecundity, coherence, internal consistency, and fertility, more closely match \\ those criteria used in art contexts and by scholars working in aesthetics. Paying closer attention to \\ the way these criteria are used in art contexts allows us to understand some evaluative and \\ developmental practices in scientific theory selection as genuinely aesthetic, enlarging the scope of \\ the goals of science. \\ Ian O’Loughlin \\ ian.oloughlin@pacificu.edu \\ Kate McCallum \\ k.mccallum@,brighton.ac.uk

\section{Acknowledgements} \\ We would like to thank the attendees of the Third Lisbon International Conference on the \\ Philosophy of Science for their comments on an earlier version of this paper, and two anonymous \\ reviewers at Philosophy of Science for their particularly careful, insightful and well-informed \\ suggestions, which have undoubtedly improved this work.
}




\section{Introduction}

Especially in the wake of Thomas Kuhn's Structure of Scientific Revolutions, researchers have been devoted to understanding the role that aesthetic judgments play in theory selection (Chandrasekhar 1990; Gingerich 1975, Kivy 1991, Kuhn 1962, J. W. McAllister 1999, Todd 2008). The claim that these judgments are aesthetic would be defensible if, in the evaluative practices in science, criteria are being applied in the same way that they are applied in the evaluative practices of art. ${ }^{1}$ Since art is not usually taken to be a straightforwardly epistemic endeavor-or at the very least, it is not taken to be primarily in the business of true (or empirically adequate) descriptions of the world - this ostensible commonality between art and science has remained a source of discussion. Scientists and mathematicians have long employed aesthetic language when assessing theories, but it is not clear whether this language tracks genuinely aesthetic judgments that drive theory selection when confronted with what may otherwise be incommensurable but competing theories. If aesthetic judgments play significant roles in theory selection, then it might appear that the preservation of progress in science (be this progress in terms of verisimilitude, empirical adequacy, or the advancement of other straightforwardly epistemic goals) may require a reduction of these ostensibly aesthetic judgments to the epistemic. In the absence of such a reduction, it can be difficult to understand how aesthetic judgments can play a legitimate role in theory selection. After all, science is

1 We take it that aesthetic judgments or criteria should not as a whole be identified with judgments of beauty; this confusion will be discussed further below. The evaluation of a work of art may involve judgments of beauty, but it certainly need not. For a thorough exploration of this dissociation, see Danto (2007). For an introduction to some of the difficulties in defining the modern notion of the aesthetic, see Zangwill (2014), especially section 3. 
standardly taken to be in the business of advancing epistemic goals. ${ }^{2}$ If this is so, then it seems these "aesthetic" judgments must be either extraneous, or reducible to epistemic categories.

Science is not always characterized, however, as narrowly or essentially epistemic. Larry Laudan not only describes the activities of science as extending beyond the epistemic, he urges philosophers of science to pay more attention to the non-epistemic components of scientific practice, writing that "philosophy of science is not, and should not be conceived as, an exclusively or even principally epistemic activity. This is because science is neither exclusively nor principally epistemic" (Laudan 2004, 15). Later in the same article, Laudan admits that the specific relationships among the roles of epistemic and non-epistemic components of scientific practice are complex; this is reason to hesitate, he writes, before characterizing these in too much detail. He goes on, however, to conclude the piece by writing, "What I have no hesitation about is my insistence on the explanatory poverty of purely epistemic values and the resultant need to talk philosophically about science in categories that go well beyond the merely epistemic" (Laudan 2004, 22).

One way to heed Laudan's exhortation is to look anew at discussions of aesthetic criteria in theory selection and development. If criteria are applied in genuinely aesthetic ways, which cannot be reduced to epistemic terms, in the context of scientific theory development and selection, then some of the very phenomena already discussed by philosophers of science lie beyond the bounds of epistemic considerations. Despite most understandings of the term 'aesthetic' going beyond judgments of beauty to include considerations of the philosophy of art (Kelly 1998, Sheppard 1987, Levinson 2003) — even a tendency to identify the two in the wake of Hegel— the treatment of aesthetic criteria by philosophers of science has sometimes suffered from a dearth of engagement

\footnotetext{
${ }^{2}$ Ernan McMullin (1983) writes that to call values 'epistemic' is to declare that they 'promote the truth-like character of science". We will maintain this characterization of 'epistemic' as truth- or truth-likeness- oriented, and we will also discuss further below.
} 
with aesthetic criteria as these are discussed and deployed in art. Robust studies comparing aesthetic criteria in art and science are lamentably rare (Todd 2008, 2), even despite the fact that in introducing the influential work that sits near the origin of so many of these discussions, The Structure of Scientific Revolutions, Thomas Kuhn explicitly cites the parallel influences of Paul Feyerabend and Stanley Cavell, in science and aesthetics respectively, in the development of his book (Kuhn 1962). In the following essay, we will defend the possibility that some of the criteria already invoked in theory selection discussions-but not those criteria most commonly named by philosophers of science as aesthetic-play a genuinely aesthetic role familiar from art contexts, thus denying the epistemic reduction while also preserving a meaningful role for aesthetic judgments in science.

\section{Using Aesthetic and Epistemic Criteria}

Comparing competing theories is a notoriously messy business. If Kuhn is right that the worldviews conferred by respective and competing theories are incommensurable in a basic sense, then it is unclear what a rational choice between such theories can look like. Preserving the rationality of the progress of science seems to require some standards or criteria that can (and should) be applied across competing theories. Even if these incommensurability difficulties are not absolute, ${ }^{3}$ trying to understand how the apples of one theory can be compared to the oranges of another has generated significant and spirited literatures (Hoyningen-Huene and Sankey 2013, Hsieh 2007, Kuhn 1977, Laudan et al. 1986). Different theories have different advantages; one may be superior with respect to explanatory scope while its competitor may be more ontologically parsimonious or more

3 It is not always clear that Kuhn believes them to be absolute in the way that, for example, Feyerabend does (Feyerabend 1975, Kuhn 1977, Sankey 1993). 
fecund. Lists of criteria, or theoretical virtues, by which we should compare the merits of competing theories vary somewhat widely, but many of these include or resemble something near to the following: ${ }^{4}$

$\begin{array}{ll}\text { Simplicity } & \text { Unifying power } \\ \text { Symmetry } & \text { Predictive accuracy } \\ \text { Fecundity } & \text { Explanatory power } \\ \text { Coherence } & \text { Consilience } \\ \text { Fruitfulness } & \text { Parsimony } \\ \text { Internal consistency } & \text { Consilience } \\ \text { Non-ad-hoc-ness } & \text { Empirical accuracy } \\ \text { Fertility } & \text { Explanatory scope }\end{array}$

However theories should be evaluated, they certainly are evaluated using what appear to be aesthetic criteria. Scientists use aesthetic terms and concepts to describe the virtues of theories under comparison, and philosophers of science regularly assume that at least putatively aesthetic criteria play an active role in theory selection and development. Very broadly, there are three possible ways to characterize these: we might say (1) that these are "merely" aesthetic, and are not significant in theory evaluation, (2) that these are actually epistemic judgments in disguise, rather than genuinely aesthetic, or (3) that they are both genuinely aesthetic and a significant part of the theory evaluation process.

$4 \quad$ This list, as written, includes concepts that may or may not be duplicates. Whether there are meaningful distinctions between, for example, fertility and fruitfulness, or simplicity and parsimony, is subject to debate. We do not mean to here take a stand on any of these controversies; our list includes characteristic criteria and errs on the side of inclusion for the sake of the arguments herein. 
The first of these is advocated by some philosophers of science who have responded to Kuhn, including Ernan McMullin (1983, 1993), who responded to Kuhn's book with the worry that these merely aesthetic bases for theory change characterize science in a dangerously subjective fashion. On this view, it is conceded that scientists do undertake aesthetic considerations in theory evaluation, but these aesthetic considerations are at worst impediments, or at best harmless and capricious tiebreakers. Cain Todd writes of this approach to aesthetic judgments, "According to what is known as the 'rational model' of science, appeals to aesthetic factors in theory assessment look to be entirely out of place" (Todd 2008, 2). If progress in science is solely a matter of proximal truth, or verisimilitude, or increasing empirical adequacy, and if these judgments are genuinely aesthetic and thus not truth- or adequacy-tracking, then they can only be superfluous in the processes of science.

The second option is advocated by Todd, who evinces skepticism about whether so-called "aesthetic" criteria for theories are genuinely aesthetic, stating that "...there are strong grounds for suspecting that what appear to be aesthetic claims may often be, if perhaps not always are, really masked 'epistemic' functional ones and the aesthetic terms at issue -- 'beautiful' and 'elegant' and so on -- must be being used in a 'qua', or metaphorical way" (Todd 2008, 17). Todd then issues a challenge: "The burden of proof lies on those who would resist such scepticism...part of their task...is to give an adequate theory of aesthetic value, appreciation, or properties that...allows us to see how theories and proofs might fit the general contours of more paradigmatic examples of objects of aesthetic appreciation, such as artworks and natural objects” (Todd 2008, 63).

Todd cites Peter Kivy's Science and Aesthetic Appreciation (Kivy 1991) and James McAllister's Truth and Beauty in Scientific Reason (J. W. McAllister 1989) as touting "aesthetic" criteria that are actually epistemic. McAllister argues that initial aesthetic judgments tend to be formed by a theory's 
likeness to other existing, successful theories. The successes of past theories refine scientists' aesthetic sensibilities, granting researchers a capability for "aesthetic induction". "According to a view that has enjoyed great popularity throughout the centuries, the aesthetic properties that are a sign of truth in theories are those exhibited by the world itself. On this view, a theory is bound to be close to the truth if it shows the same aesthetic properties as the natural phenomena; otherwise it must be false. This view is expressed most often in regard to the properties of simplicity and symmetry" (McAllister 1998, 176).

"Many scientists claim to be able to tell by means of aesthetic judgment how close a theory is to the truth," McAllister writes (McAllister 1998, 174), but "the evidence that any aesthetic property of theories is a sign of truth is at present scarce" (McAllister 1998, 183). McAllister separates beauty from 'truthlikeness', setting up two strands that follow “...Einstein's view of the desiderata of theories according to which theory-comparison may be conducted on two levels: an external level appertaining to the relationship of the theory to experiment, and an internal one referring to its inner conceptual structure” (McAllister 1989, 29). McAllister considers simplicity, symmetry, analogical interpretability, and consistency with metaphysical presuppositions as criteria in aesthetic judgements. He argues that theories tend to be judged as beautiful if they are structurally similar to existing work and (at least initially) considered ugly otherwise.

It is unsurprising that McAllister is taking Einstein's lead; Einstein himself was interested in the virtues of aesthetics in theory selection, and the adoption of relativity over Newtonian mechanics is an instance of theory selection ripe for aesthetic investigation. This example is worth our consideration: Subrahmanyan Chandrasekhar touts general relativity as "the most beautiful of all existing theories" (Chandrasekhar 1984), citing as his guiding criteria Bacon's dictum that beauty requires some "strangeness in the proportion" and Heisenberg's proposition that "beauty is the 
proper conformity of the parts to one another and to the whole." ${ }^{5}$ The positing and adoption of general relativity provided the kind of fundamental shift in perspective that makes for rich philosophical analysis. The judgment that relativity is preferable to Newtonian mechanics seems to involve weighing incommensurable qualities against one another-a nearly impossible feat of metajudgment, as it seems - and yet also seems emblematic of the rational progress of science. Making sense of this apparent tension, in cases like this one, by framing it in terms of genuine and extraepistemic aesthetic judgments is something we will return to below. On McAllister's view, however, these judgments count as both aesthetic and truth-conducive.

McAllister grants judgments such as these 'aesthetic' status. However, his treatment of 'aesthetic' is problematically broad and subservient to epistemic goals, including, for example, Einstein's "aesthetic" preference for deterministic theories. Examples like this serve McAllister well; an aesthetic preference for determinism can only be an induction on the past successes of determinism, since there is nothing recognizably art- or beauty-oriented in such a predilection. Crucially, McAllister ties these so-called aesthetic judgments to unconscious predictions about empirical adequacy and predictive success. As Todd notes, this seems to render such judgments not truly aesthetic (Todd 2008, 1).

We are advocating for the third possibility: that aesthetic judgements belong in theory evaluation and that they are truly aesthetic. The tendency to focus on simplicity and symmetry is something we consider further; we will argue that an exclusive focus on these has been a problematic limitation in treatments of aesthetic judgments of scientific theories. We take up Todd's suggestion to look at "more paradigmatic examples of objects of aesthetic appreciation, such as artworks and natural objects" (Todd 2008, 63), and we discuss the distinction between aesthetic

\footnotetext{
${ }^{5}$ Both as quoted in Chandrasekhar $(1984,5)$. The substance of these criteria, and their similarities to criteria deployed in art scholarship, will be further investigated below.
} 
judgements of natural beauty and of artistic excellence. Focusing on the latter, we highlight the work of art theorists who characterize aesthetic judgment in terms of appreciation for internally coherent, fertile, alternative ways of seeing, a view which we hope to show has important features in common with the way that a scientific theory might be evaluated as a coherent, fecund, internally consistent and genuinely alternative way of understanding phenomena. By attending to evaluative practices in art we can make observations about aesthetic judgements that will provide a stable basis for discussions of the aesthetics of science. Our main contention will be that these evaluative practices - regarding the target (artwork or theory) as a complete and inhabitable alternative perspective, and evaluating in terms of criteria like fertility, consistency, and non-adhocness-are importantly common to both art and science. We will show that criteria such as coherence and fecundity appear to be applied in genuinely similar ways in science and in art, and this provides good reason to look beyond simplicity and symmetry in searching for the role of aesthetic judgments in science.

3. The Aesthetics of the Simple and Symmetric

Much has been written about theory selection, and about what kind of criteria we do or should employ, and much has been written about the aesthetic criteria and judgments in science and theory evaluation. Too much of what has been written, however, about aesthetic criteria or judgments, seems to point at a very limited number of criteria. McAllister writes of the notion that there are meta-theoretical criteria which are also aesthetic, "this view is expressed most often in regard to the properties of simplicity and symmetry" (McAllister 1998, 176), two terms that crop up 
very regularly in discussions of the aesthetics of science. ${ }^{6}$ Simplicity and symmetry are interesting, but neither places comfortably as the most essential criterion in aesthetic judgments within the domain of art, nor does the way these are wielded in science match very closely the way they are wielded in art. Each of these deserves brief consideration.

As McAllister notes, simplicity is the virtue most often mentioned in discussions of aesthetic judgments' roles in theory selection. ${ }^{7}$ As a feature of proofs and theories, simplicity might appear to be a straightforward matter, though philosophers of science have shown this to be hardly so (Boyd 1985, Sober 2015). Although the details have generated much controversy and productive discussion, philosophers and scientists mainly agree that simplicity is an important desideratum in theory development. ${ }^{8}$ Upon reflection, the prevailing attitude that deems simplicity a primary mark of aesthetic judgment in science is somewhat curious; simplicity hardly plays this central role in aesthetic judgments elsewhere. For example, one has only to look at the controversy surrounding works of minimalist art such as Martin Creed's The Lights Going On and Off to see that simplicity does not reliably predict widely accepted judgments of artistic merit. Simplicity may have a place as a factor in artistic judgments, particularly when it is unexpected, if for example an artwork succeeds in being very insightful or transformative despite its simplicity; but it is clearly unlikely to be accepted as a chief criterion.

$7 \quad$ Richard Boyd writes that what philosophers of science call simplicity or parsimony, scientists themselves simply call elegance or beauty (Boyd 1985, 349).

8 The work of Elliott Sober is central among discussions of simplicity in science in recent decades (e.g. Sober 1975, 2015), and Sober writes, "Einstein (1933) spoke for many [scientists] when he said that 'it can scarcely be denied that the supreme goal of all theory is to make the irreducible basic elements as simple and as few as possible without having to surrender the adequate representation of a single datum of experience.' This influential point of view holds that the search for simple theories is not optional' rather, it is a requirement of the scientific enterprise" (Sober $2015,2)$. 
Matthew Inglis and Andrew Aberdein have recently designed and executed a study of judgments in mathematics (Inglis and Aberdein 2014). The authors of the study presented mathematicians with a number of proofs, soliciting single-word judgments from these mathematicians, and then gathered together and correlated the responses using factor analysis. ${ }^{9}$ Firstly, their factor analysis yielded an "aesthetics" factor that bore no correlation with the term 'simple'. The more straightforwardly epistemic terms such as 'plausible', 'expository', 'explanatory' or 'informative' did not correlate strongly with beauty, as the authors point out, “...suggesting that there is no strong relationship between aesthetic and epistemic judgements" (Inglis and Aberdein 2014, 101). However, they did find correlations between beauty and terms such as 'enlightening', 'insightful', 'striking', 'inspired', and 'exploratory': 'Proofs which are 'enlightening', 'fruitful', and 'insightful', for instance, will tend to score highly on the aesthetics and utility dimensions (these adjectives have reasonably high loadings on both dimensions)" (Inglis and Aberdein 2014, 101). Before following up on this intriguing connection between aesthetics and fruitfulness, let us briefly consider symmetry in science and aesthetic judgment.

'Symmetry' has many meanings. In considering its use in science, and especially in physics, Katherine Brading and Elena Castellani survey several of these, from the general "proportion relation... with the function of harmonizing the different elements into a unitary whole," to an "equality relation between elements that are opposed," to the special technical definitions in crystallography or group theory (Brading and Castellani 2003, 3). In theory selection and development the preservation of these symmetries is a significant desideratum. That is, unexplained

9 Such a study is inherently difficult to design, and it is difficult to argue that their results can indicate anything more than correlative tendencies, as they themselves own. However, with that proviso in mind, the correlative results of the study in question still bear on discussions of aesthetics in science in interesting ways. 
asymmetries are assumed to be indicative of theoretical shortcomings, and revisions to a theory that allow for more symmetry preservation are taken to demonstrate progress. The role and nature of these assumptions, that asymmetry requires additional reasons or explanation, whereas symmetry does not, have generated significant controversy and discourse (Rosen 1995), but it is not uncommon to treat symmetry as a strong indicator of beauty. McAllister places symmetry alongside simplicity as one of the two properties most frequently cited as aesthetic in judging theories (McAllister 1998, 176), and he is not alone; as I.C. McManus writes, "Symmetry and beauty are often claimed to be linked, particularly by mathematicians and scientists" (McManus 2005, 157), and this is evidenced in many reflections by scientists and mathematicians on their work (Weinberg 1993, Lincoln 2013, Paul Dirac quoted in Barrow 1988, 345, Stewart 2008).

In scientific contexts it is no straightforward matter that the same concept of symmetry is at work as is at work in the bilateral or radial symmetry demonstrated by a work of visual art. Giora Hon and Bernard Goldstein (2008) have argued that the concept of symmetry as it is used in modern mathematics and physics is an invention of the modern age, and has little to do with the visual sense of symmetry we might employ in evaluating a painting. If Hon and Goldstein are right, then this is already one reason for scepticism about symmetry's place as a primary candidate for genuinely aesthetic criteria in science-the concept that mathematicians use may bear little relations to the concept artists use-but even if these concepts share more than Hon and Goldstein allow, an investigation of the comparatively minor role played by symmetry in art will show that the role of symmetry in criteria for aesthetic evaluation is not a straightforward or primary one.

Even Immanuel Kant, the originator of modern aesthetics, discusses the limitations of symmetry in aesthetic objects in his Critique of Pure Judgement, stating that "all stiff regularity (such as borders on mathematical regularity) is inherently repugnant to taste, in that the contemplation of it affords us no lasting entertainment... and we get heartily tired of it.” (Kant 2008 (1790), 80) 
Art critics more commonly discuss a kind of tension between symmetry and asymmetry. In The Sense of Order, Ernst Gombrich characterises this tension as “.... a struggle between two opponents of equal power, the formless chaos, on which we impose our ideas, and the all too formed monotony, which we brighten up by new accents" (Gombrich 1994, 113-4).

It is the relationship between symmetry and asymmetry, the selective breaking of rhythms and introduction of unexpected forces, that is important here; the implication is that an artwork that relied too heavily on either of the pair would risk sliding into directionlessness or, worse, tedium. ${ }^{10}$

If we are to take seriously the notion that some judgments made by scientists-whether they are appraising monumental revolutions such as heliocentrism and natural selection, or whether they are engaged in the development of subtle revisions to everyday, "normal science" theorizing—are genuinely aesthetic, we have reason to look beyond considerations of simplicity and symmetry. This is not to say that these do not play genuinely aesthetic roles in theory selection, but only that it has been too hastily assumed that aesthetic considerations in science must be limited to these criteria.

\section{Two Views on Science-Art Parallels}

In The Omniscienter, Peter Kosso discusses aesthetic appreciation in evaluating scientific theories. Kosso identifies (rightly and importantly, in our view) criteria such as coherence, fruitfulness, non-ad-hoc-ness, and internal consistency as genuinely aesthetic criteria that are also sought in theory selection and development in science. ${ }^{11}$ Recall Chandrasekhar's (and by extension,

10 See also an informed and nuanced discussion of symmetry and asymmetry in McManus (2005).

11 Kosso includes some important points about ad-hocness: "Ad hoc ideas usually dangle, in the sense of being connected only to the one claim they are meant to support, the one phenomenon 
Heisenberg's) aesthetic praise of general relativity's "proper conformity" among the parts and the whole: what beauty there is in relativity does not easily reduce to simplicity, and Kosso's characterization of aesthetic criteria are better suited to capture these judgments than are traditional perspectives on the aesthetics of theories. This broadening of our understanding of aesthetic criteria as they are used in scientific theory is an important advance beyond the focus on simplicity and symmetry as "aesthetic" criteria for theories, but it is underserved by Kosso's subsequent reduction of these criteria to the epistemic. "The central point I hope to make is that there is an epistemic role for the aesthetic feature I have been describing as interconnectedness, propriety of fit, structural necessity, and theoretical rigidity" (Kosso 2002, 47). It is not difficult to find a place for these features in judgments of scientific theory: the $19^{\text {th }}$-century biologist, for example, who is contemplating Darwin's natural selection and its virtues must certainly be impressed by the theory's interconnectedness and fecundity, by the gestalt shift made available by this perspective. Kosso identifies gestalt appreciation of a work of art with the experience of understanding, an aim he explicitly defines as epistemic; this is a move that is by no means unproblematic, as demonstrated by the literature on understanding in, for example in Regt et al. (2009) or Grimm (2006).

Historically, scientific understanding has been a topic that philosophers of science have been cautious to approach, although there is reason to believe that this reticence has been fading in recent years (De Regt et al. 2014). A recent article by Catherine Elgin also deftly illustrates hitherto underappreciated parallels between the respective functions of artworks and scientific theories with respect to understanding (Elgin 2017), but Elgin's characterization of 'understanding' is more

they are to save. This creates loose ends and thus diminishes the beauty of the theoretical framework" (Kosso 2002, 42). 
pluralistic and less reductive than Kosso's. ${ }^{12}$ Elgin describes works of art as exemplifying possible situations or experiences through constructed fictions, drawing a parallel with the models and thought experiments used in scientific enquiry and arguing that art, "like science, embodies, conveys, and often constitutes understanding” (Elgin 2017, 27). Elgin does broadly categorize this understanding, as well as the functions of artworks and theories, as "epistemic", but explicitly denies that this need have anything to do with truth or truth-likeness, in either art or science. "Very roughly," Elgin writes, “epistemically rewarding works of art reorient us, enabling us to see things differently from the ways we saw them before" (Elgin 2017, 4). This usage of 'epistemic', including the way that "epistemically rewarding" artworks reorient us, must accord with the spirit of Laudan's exhortation to broaden our understanding of the aims of science, even if Laudan and Elgin might disagree whether it is most useful to deem these aims "epistemic", that is, to draw the boundaries of the concept of 'epistemic' so as to include criteria and functions such as these.

At this point a potential objection may be that to de-emphasise simplicity and symmetry, and to exclude all things epistemic, from an investigation of aesthetic judgments in science is to lose sight of our target altogether. What reason is there, in the absence of these, to claim that we are talking about aesthetic judgments in theory selection at all? After all, commonly cited examples of aesthetics in theory selection, such as the selection of heliocentrism over the Ptolemaic model, seem to exemplify aesthetic judgment that is grounded in simplicity and which aims at truth or verisimilitude. But although the adoption of heliocentrism is sometimes characterized as driven by

12 Elgin emphasises the plurality of possible interpretations (Elgin 2017, 38), an important plurality to recognise to avoid creating an untenably didactic role for the art object. Any portrayal of the artwork that leads to an artwork containing one, single lesson to teach is bound to fall short of characterizing the richness inherent in the viewer's experience and understanding of art. It is perhaps telling that in her concluding sentence, Elgin literally pluralizes this term, writing about the trajectories followed by art and science in "their pursuit of understandings" (Elgin 2017, 23, emphasis added). 
simplicity concerns (Sober 2015, 14-17), the view that the motivations for this adoption boil down to mere simplicity is far from consensus, and has been long contested. "The geocentric and the heliocentric models of our planetary system are regarded by conventionalists as empirically equivalent and even as equivalent modes of speech; and it has been claimed and repeated that the sole reason for preferring the heliocentric system is its simplicity relative to the geocentric image, since-so the contention runs-there is really no reason to single out one system of reference (the Copernican) to another (the Ptolemaic)" (Bunge 1961, 138).

But Bunge adds that "both affirmations are false," and that the Copernicus-Kepler system "was not adopted because of its great simplicity." Bunge goes on to enumerate the criteria by which the Copernicus-Kepler system was affirmatively judged, citing among these virtues of the heliocentric system features such as fertility, interrelations with other elements of our worldview, and the way that the heliocentric system is a "conceptual reconstruction of facts" (Bunge 1961, 139). Bunge is primarily concerned with examining simplicity claims, and not with investigating the aesthetic or otherwise character of these judgments, but even so it is worth pointing out that his characterization of the adoption of heliocentrism as motivated by judgments that the new theory offered a fertile, coherent reconceptualization is more suggestive of the aesthetic criteria provided by Elgin and Kosso-interconnectedness or propriety of fit, a reorienting of perspective — than it is of a simplicity judgment which aims solely or narrowly at truth and knowledge. Kosso and Elgin begin to demonstrate how some of the features of theory selection already emphasized in canonical examples accord with robustly aesthetic features, even if both Kosso and (to some extent) Elgin still construe these judgments as broadly epistemic.

Another illuminating criticism of Kosso's work can be made. He explicitly draws a comparison with the appreciation of a work of art. "One aspect of beauty in a work of art is in the proper fit and balance of the parts in their relation to one another and their place in a coherent 
whole. [...] There is a kind of necessity and inevitability in the quality of each element in its connections to other elements and its place in the pattern" (Kosso 2002, 41).

As observed above, leading thinkers in modern aesthetics observe that works of art that adhere simply to principles of harmony and completeness, without any element of asymmetry to counterbalance it, run the risk of dullness (Kant 2008, Gombrich 1994). It would seem, then, that this account of art may be somewhat lacking; in placing such strong emphasis on fit, balance and coherence, Kosso may do a disservice to the diversity and disruptive power of art. Kosso's phrasing is telling; he begins by seeking qualities that might justify the attribution of beauty to a work of art. Indeed, a problem in discussions from the philosophy of science is their tendency to identify aesthetic judgments with judgments of beauty, whereas in discussions of art, judgments are certainly aesthetic but often not tied to beauty. Todd's reference to “...paradigmatic examples of objects of aesthetic appreciation, such as artworks and natural objects" (Todd 2008, 63) raises an interesting question; he confidently groups artworks and natural objects together, but a closer look at theories of contemporary art reveals them to be uncomfortable bedfellows.

In The Abuse of Beanty, Arthur C. Danto describes how beauty appears to have been removed from definitions of art for the last hundred years. He makes some criticisms of the extent to which the question of beauty has become taboo in art but remains in favor of dethroning beauty as an essential feature, characterizing art instead as dealing with broader human sensibility (Danto 2007). We must accept, then, that the kind of aesthetic judgement that pertains to art is not necessarily going to be identifiable with a judgment of beauty. It seems reasonable to look to some characteristics of theories of art and artistic appreciation, which might propose ways to think about aesthetic judgments that draw upon some of the same criteria employed in theory selection in 
science, and, more importantly, do work grounded in these criteria that is robustly similar to work done by these same criteria in theory selection and development.

5. Ruptures and Rules that Cannot be Formulated

The scholarship of art theory is wildly diverse, but we have noted certain recurrent features to some approaches that seem relevant to the question at hand. One of the foremost thinkers in contemporary art theory is Jacques Rancière, whose theory of art calls for alternative ways of seeing that he claims we have need of in order to see the assumptions and rules of representation that form our own. Concerned primarily with the political potential of art, Rancière's theory revolves around the "distribution of the sensible" ("partage du sensible"). "The distribution of the sensible reveals who can have a share in what is common to the community based on what they do and on the time and space in which this activity is performed [...] it defines what is visible or not in a common space, endowed with a common language, etc. [...] Politics revolves around what is seen and what can be said about it, around who has the ability to see and the talent to speak, around the properties of spaces and the possibilities of time" ( Rancière 2013, 12-13).

For Rancière, then, the community of sense is made up of what is visible, sayable and therefore doable among a certain social group. Rancière calls for art to be an act of "dissensus" conflicts "between two regimes of sense, two sensory worlds" (Rancière 2008) that allow us to pierce through the walls of our own system and perceive something of the rules and norms that guide our own experience. He believes that aesthetic experience should be "...a multiplicity of folds and gaps in the fabric of common experience that change the cartography of the perceptible, the thinkable and the feasible" (Rancière, 2008). For Rancière, no one of these regimes of sense is subsumed by another; rather, the conflict between two regimes simultaneously makes previously 
invisible assumptions apparent, and proposes an alternative. This recollects not only Chandrasekhar's praise of general relativity as involving an unexpectedness, a strangeness of proportion (Chandrasekhar 1984, 6), but also Bunge's characterization of heliocentrism as a "conceptual reconstruction" (Bunge 1961, 140).

Another interesting parallel comes from one of the most important developments of the last three decades, the affixing of the term 'Relational Aesthetics' to an emerging tendency in contemporary art to focus on experimental social spaces taken to be proposals for new ways of being and relating, as alternative worlds or temporary models_-for example, Carsten Höller's slides (as in Test site, Tate, 2006-7), which ask people to adopt a different way of moving and travelling in familiar spaces. These are seen as experiments with a serious role to play, and the theorist who created the name, Nicolas Bourriaud, asks them to be analogous to a social experiment made into a working experience: "what really good artists do is to create a model for a possible world, and possible bits of worlds [...] any artwork is a relation to the world made visible" ("Stretcher | Features | Nicolas Bourriaud and Karen Moss,” n.d.). Bourriaud also lays down stringent requirements for the functionality of such models, stating that "the role of artworks is no longer to form imaginary and utopian realities, but to actually be ways of living and models of action within the existing real, whatever the scale chosen by the artist" (Bourriaud 1998, 13). Bourriaud sees these not just as imaginary play worlds, but as worlds that we can use and that will inspire future ways of being: fertile, coherent, operational.

The requirement for these worlds to be functional recalls Iris Murdoch's writings on art, which draw upon a development of the Kantian notion of appreciation of purposiveness. Murdoch writes that the work of art exists "...in accordance with a rule we cannot formulate" (Murdoch 1959, 43). Kant's aesthetic appreciation involves the recognition of a purposiveness without a 
purpose, in that rather than fulfilling some kind of objective end, the purposiveness instead refers back to the subject and this brings the intuition and understanding into a spontaneous harmony. ${ }^{13}$ Murdoch emphasises that true appreciation of an art object entails that it cannot simply be subsumed into the old way of seeing, but has an integrity in itself that operates in some new, rich, and incommensurable way. Engaging with a domain that belongs to itself and cannot be assimilated into our prior understanding is a theme Murdoch returns to in various discussions: "If I am learning, for instance, Russian, I am confronted by an authoritative structure which commands my respect. The task is difficult and the goal is distant and perhaps never entirely attainable. My work is a progressive revelation of something which exists independently of me” (Murdoch 2001, 89).

Her discussions of art are also linked explicitly to her conception of love, "the extremely difficult realisation that something other than oneself is real" (Murdoch 1959, 42). For Murdoch, the work of art has its own independent existence, following its own logics or rules, even though these cannot be expressed as such. To appreciate a work of art is to engage with, to inhabit, a domain that is genuinely other. What a work of art can do, not only for Murdoch but also for Rancière, or Bourriaud, is to provide a novel system of things, internally coherent and related but also abundantly complex — to lead us into a whole discoverable world or way of seeing, independent of and incommensurable with our own, by a shift in perspective.

The independent existences of incommensurable worlds, which are only mutually comprehensible in partial and difficult ways, is a collection of notions that is already familiar in the philosophy of science and from discussions of theory selection and development. Paul Feyerabend championed a view of scientific work and progress that embraced just this aspect of Kuhn's

13 Although Kant explicitly rejects any epistemic aspect to aesthetic judgements, a good argument has been made that justifies a Kantian interpretation of the appreciation of mathematical proofs in Breitenbach (2015). 
considerations. Feyerabend characterizes the incommensurability of competing theories as not only acceptable but crucial to the function of science. In asking how we can possibly evaluate our theoryladen worldview, he answers that we must conjure dream-worlds, outside of and incommensurable with the world and worldview we inhabit. "The answer is clear: we cannot discover it from the inside. We need an external standard of criticism, we need a set of alternative assumptions or, as these assumptions will be quite general, constituting, as it were, an entire alternative world, we need a dream-world in order to discover the features of the real world we think we inhabit" (Feyerabend 1975, 22).

So the investigation and subsequent adoption of heliocentrism or natural selection, on this view, did not involve a comparison of relative simplicities, but instead involved the inhabiting of a fertile alternative world that allowed a reconceptualization of the facts before us. This emphasis on the value of being able to take on an entirely new perspective, to view the world through a framework that is incommensurate and juxtaposed with the one we have begun with exhibits striking similarities to ideas that have been expressed about the value of art. Feyerabend is talking about the process of developing and assessing different theories, but Proust famously says just this of art: that its value lies in art enabling us to see our world through new eyes, to see a whole system of things that are at once familiar and unfamiliar, and that this seeing is "the only real voyage of discovery" (Proust 1929).

A key point here is the way in which these ideas—rich, fruitful, and complex though they be-resist reconciliation with the way we normally view things—our prior conceptual frameworks are unable to subsume or make sense of these new ideas. This is not just about (symmetry-like) 
completeness: it is surprising or change-bringing coherence, a rupture that nonetheless works. ${ }^{14}$

McAllister cites examples of beauty being ascribed to theories that echo existing thought, and judgments of ugliness going with newness. “...theories which maintained aesthetic continuity with their successful predecessors have been pronounced beautiful while their competitors which lacerated that continuity have been initially condemned as ugly or displeasing, only for those judgements to be gradually reversed as the aesthetically innovative theory proved its superior possession of indicators of truth" (McAllister 1989, 40). These may be judgments that lie more comfortably with those of beauty, whereas art is expected to be disruptive and new. Where our understanding of beauty tends to be associated with pleasure, harmony and enjoyment, works of contemporary art are expected to surprise, to sometimes offend, to break through the expected.

The three perspectives that we have outlined differ in many ways, but each sketches a picture of the work of art as aiming to offer a coherent perspective that allows fertile and meaningful exploration according to a self-contained logic particular to itself. These point to contours which are familiar from discussions of theory selection in philosophy of science. Kosso emphasizes the ways that scientific theories are expected to be self-contained, interconnected, inhabitable and coherent ways of looking at otherwise sterile facts. Elgin draws our attention to the way that scientists seek models, theories, and experiments that operate by concocting fictional worlds, writing that "experiments...distance, isolate, and purify. They set up circumstances, sometimes quite unrealistic circumstances, and see how things play out. They devise contexts, including and omitting as

14 If this is so, then we would expect the result in the Inglis and Aberdein study above, that aesthetic judgments in the sciences (in this case of mathematical proofs) cluster around terms like 'striking', 'exploratory', 'insightful', and 'fruitful' (Inglis and Aberdein 2014, 101). 
necessary to bring out the features they seek to highlight. They can be vehicles for discovery." ${ }^{\prime 5}$ On a larger scale, Kuhnian paradigms are taken to be respectively incommensurable ways of delivering intelligibility and fruitfulness. This picture of science, one in which key tools involve the construction and inhabiting of ways of seeing which are evaluated in terms of coherence, fecundity, internal consistency, and non-ad-hoc-ness, depicts the process familiar from art scholarship, where an aesthetic work is viewed as a way of inhabiting a particular, alternative, coherent and fruitful perspective.

An objector may worry that the respective aims of art and science just do fundamentally differ, and that any parallels between them must be in name only. Importantly, and as we hope to have shown, these parallels do not appear to be superficial. Unlike the example of symmetry discussed above, for which we saw that markedly different things may be meant by the term in different contexts, we here see that there are criteria that really do appear to be applied in similar ways in judgments of theories and in judgments of works of art. Bunge's astronomers who are impressed by the fertile reconceptualizations offered by heliocentrism, or Feyerabendian biologists seeking to inhabit the dream-world of natural selection in order to understand the real world, seem to be involved in processes genuinely similar to the art experience of Rancière, wherein the viewer is impressed by the change in the cartography of the perceptible, or the incommensurable and inhabitable perspectives of Murdoch or Bourriaud. Elgin notes the commonalities in scientific theories and artworks setting up hypothetical spaces, and we take these judgments to be judgments on the self-consistency, insightfulness and unexpectedness of such fictions.

15 Elgin 2017, 14. Although she is in this passage characterizing experiments, Elgin also spells out the way that models, laws, and formulas operate in this fashion, constructing fictive and coherent illustrations of the interrelations within a system. 
Elgin takes that commonality between science and art to point to epistemic qualities in art. Instead we contend that, given that the way these criteria are used in art is without any reference to truth or truth-likeness, the subsumption under the category of the epistemic is a problematic one. Although a property such as verisimilitude may entail properties like coherence and internal consistency, this entailment is not reciprocal; a bearer, be it a work of art or a scientific theory, can exhibit properties of fecundity, coherence, non-ad-hoc-ness, and so forth, in the absence of any tendency toward or away from truth. In this we depart from both Elgin and Kosso, each of whom associates aesthetic judgments with understanding, which they in turn identify as epistemic. We consider this broad construal of 'epistemic' problematic. Our contention is that these ought not be branded epistemic, in science or in art, and that 'epistemic' should be reserved—as it is reserved by Laudan and others - for those pursuits oriented toward truth (or at least verisimilitude) and belief. Identifying these aesthetic processes with the epistemic even in art contexts seems to risk robbing art of a self.

\section{Conclusion}

In his 2008 article, Cain Todd concludes that those criteria deemed "aesthetic" in philosophy of science are really epistemic criteria in disguise. He argues that existing work touting the aesthetic virtues of theories—-for example, that of James McAllister-actually provides good reason to accept these criteria as fundamentally epistemic, and that they so far point only to epistemic goals as the aim of science. However, Todd does not argue that there is no possible room in theory selection for genuinely aesthetic criteria. He leaves the question open, insisting that he has only shown that existing characterizations of so-called aesthetic criteria in theory selection fail to establish any genuinely aesthetic criteria, and shifting the burden of proof onto those who would claim that 
elements of theory selection are aesthetic in a way that is not reducible to epistemic criteria and goals. We return to Todd's call for “.... an adequate theory of aesthetic value, appreciation, or properties that...allows us to see how theories and proofs might fit the general contours of more paradigmatic examples of objects of aesthetic appreciation" (Todd 2008, 63).

Someone following Todd may object that we have not done this, that we have failed to provide a "theory of aesthetic value." Instead we have encouraged attendance to a number of examples from both art and science which, although utilizing and sharing a common family of terms and concepts - fecundity, coherence, inhabitable perspectives, unexpected breaks and ruptures with the standing worldview, insightful and consistent alternative ways of seeing-fail to add up to a simple or single formula of the aesthetic that is deployed respectively in these contexts. Todd asks for an analysis of the aesthetic that will provide a basis for making such judgments of the features of theory selection. None of the above considerations could be said to fully respond to this call, but we hope to have shown that consideration of contemporary aesthetic theory has the potential to provide the equipment to construct such an account.

In furnishing this partial response to Todd, we do hope to be taking a step in this direction. By enlarging our concept of the aesthetic to include more than judgments of beauty, and by highlighting the ways that theories and theorists of art draw our attention to properties like fecundity, fertility, coherence, and non-ad-hoc-ness at least as much as-if not more than-they do to properties like simplicity or symmetry, we hope to connect discussions of theory selection criteria and the aesthetic features thereof with discussions of art along new lines. Indeed, some of the language used in discussions of art runs strikingly parallel to some of the language used to discuss theory development and criteria in science, in ways that, we contend, have gone underappreciated. Whether or not there are genuinely aesthetic criteria grounded in the simplicity or symmetry of a theory, there is also good reason to think that valuing a theory (or work of art) on the basis of the 
fecundity and internal coherence of the world it presents, at least in some cases, performs a genuinely aesthetic function. If we are seeking to consider science in a light that extends beyond the epistemic, we perhaps need look no further than some of the uses to which we put these criteria that are already counted among the legitimate goals of theory development. 


\section{References}

Barrow, John D. The World within the World. Oxford England: Clarendon Press, 1988.

Bourriaud, Nicolas. Relational Aesthetics. Dijon: Les Presse Du Reel, 1998.

Boyd, Richard. 'Observations, Explanatory Power, and Simplicity: Toward a Non-Humean Account'. In The Philosophy of Science. MIT Press, 1991.

Brading, Katherine, and Elena Castellani, eds. Symmetries in Physics: Philosophical Reflections. Cambridge, U.K. ; New York: Cambridge University Press, 2003.

Breitenbach, Angela. 'Beauty in Proofs: Kant on Aesthetics in Mathematics'. European Journal of Philosophy 23, no. 4 (1 December 2015): 955-77. https://doi.org/10.1111/ejop.12021.

Bunge, Mario. 'The Weight of Simplicity in the Construction and Assaying of Scientific Theories'. Philosophy of Science 28, no. 2 (1961): 120-49.

Chandrasekhar, S. 'The General Theory of Relativity: Why "It Is Probably the Most Beautiful of All Existing Theories"”. Journal of Astrophysics and Astronomy 5, no. 1 (1 March 1984): 3-11. https://doi.org/10.1007/BF02714967. . Truth and Beauty: Aesthetics and Motivations in Science. New edition edition. Chicago, Ill.: University Of Chicago Press, 1990.

Danto, Arthur Coleman. The Abuse of Beauty. 21st edition. Chicago, Ill: Open Court Publishing Co ,U.S., 2007.

De Regt, Henk W., Sabina Leonelli, and Kai Eigner. Scientific Understanding: Philosophical Perspectives. University of Pittsburgh Press, 2009. 
Elgin, Catherine. 'Nature's Handmaid, Art'. In Thinking about Science, Reflecting on Art: Bringing Aesthetics and Philosophy of Science Together, edited by Otávio Bueno, George Darby, Steven French, and Dean Rickles, 1 edition. London; New York: Routledge, 2017.

Feyerabend, Paul K. Against Method. London ; New York: Verso, 1975.

Gingerich, Owen J. “Crisis” versus Aesthetic in the Copernican Revolution.' Vistas in Astronomy, no. 17 (1975): 85-95.

Gombrich, E. H. The Sense of Order: A Study in the Psychology of Decorative Art. 2nd edition. London New York: Phaidon Press, 1994.

Grimm, Stephen R. 'Is Understanding a Species of Knowledge?' The British Journal for the Philosophy of Science 57, no. 3 (2006): 515-35.

Hoyningen-Huene, Paul, and Howard Sankey. Incommensurability and Related Matters. Vol. 216. Springer Science \& Business Media, 2013.

Hsieh, Nien-hê. 'Incommensurable Values'. In The Stanford Encyclopedia of Philosophy, edited by Edward N. Zalta, Spring 2016. Metaphysics Research Lab, Stanford University, 2016. https://plato.stanford.edu/archives/spr2016/entries/value-incommensurable/.

Inglis, Matthew, and Andrew Aberdein. 'Beauty Is Not Simplicity: An Analysis of Mathematicians' Proof Appraisals'. Philosophia Mathematica 23, no. 1 (2014): 87-109.

Kant, Immanuel. Critique of Judgement. Simon and Schuster, 2008.

Kelly, Michael, ed. Encyclopedia of Aesthetics. New York: OUP USA, 1998.

Kivy, Peter. 'Science and Aesthetic Appreciation'. Midwest Studies in Philosophy 16, no. 1 (1991): 180-95. 
—. 'What Makes" Aesthetic" Terms Aesthetic?' Philosophy and Phenomenological Research 36, no. 2 (1975): 197-211.

Kosso, Peter. 'The Omniscienter: Beauty and Scientific Understanding'. International Studies in the Philosophy of Science 16, no. 1 (2002): 39-48.

Kuhn, Thomas S. 'Objectivity, Value Judgment, and Theory Choice'. Arguing About Science, 1977, 74-86. . 'The Structure of Scientific Revolutions Vol.', 1962.

Laudan, Larry. 'The Epistemic, the Cognitive, and the Social'. Science, V alues, and Objectivity, 2004, 14-23.

Laudan, Larry, Arthur Donovan, Rachel Laudan, Peter Barker, Harold Brown, Jarrett Leplin, Paul Thagard, and Steve Wykstra. 'Scientific Change: Philosophical Models and Historical Research'. Synthese 69, no. 2 (1986): 141-223.

Levinson, Jerrold. The Oxford Handbook of Aesthetics. Oxford University Press, 2003.

Lincoln, Don. 'Symmetry: How Beautiful Math Makes Elegant Physics'. The Nature of Reality (blog), 25 April 2013. http://www.pbs.org/wgbh/nova/blogs/physics/2013/04/symmetry-how-beautifulmath-makes-elegant-physics/.

McAllister, James W. Beauty and Revolution in Science. Cornell University Press, 1999. . 'Is Beauty a Sign of Truth in Scientific Theories? Why Are Some New Theories Embraced as Beautiful, Others Spurned as Ugly? Progress in Science May Require That Aesthetic Ideals 'Themselves Change'. American Scientist 86, no. 2 (1998): 174-83.

—. 'Truth and Beauty in Scientific Reason'. Synthese 78, no. 1 (1989): 25-51.

McManus, Ian Christopher. 'Symmetry and Asymmetry in Aesthetics and the Arts'. European Review 13, no. S2 (2005): 157-80. 
McMullin, Ernan. 'Rationality and Paradigm Change in Science', 1993.

'Values in Science'. In PSA: Proceedings of the Biennial Meeting of the Philosophy of Science Association, 1982:3-28. Philosophy of Science Association, 1982.

Murdoch, Iris. The Sovereignty of Good. 2 edition. Princeton, NJ: Routledge, 2001.

—. 'The Sublime and the Good'. Chicago Review 13, no. 3 (1959): 42-55.

https://doi.org/10.2307/25293537.

Proust, Marcel. The Captive. Translated by CK Scott-Moncrieff. A. \& C. Boni, 1929.

Rancière, Jacques. 'Aesthetic Separation, Aesthetic Community: Scenes from the Aesthetic Regime of Art'. Art \& Research 2, no. 1 (2008): 1-15.

- The Politics of Aesthetics. A\&C Black, 2013.

Rosen, Joe. Symmetry in Science: An Introduction to the General Theory. Springer, 1995.

Sankey, Howard. 'Kuhn’s Changing Concept of Incommensurability'. The British Journal for the Philosophy of Science 44, no. 4 (1993): 759-74.

Sheppard, Anne DR. Aesthetics: An Introduction to the Philosophy of Art. Oxford University Press on Demand, 1987.

Sober, Elliott. Ockham's Razors. Cambridge University Press, 2015.

- Simplicity. Clarendon Library of Logic and Philosophy. Oxford, New York: Oxford University Press, 1975.

Stewart, Ian. Why Beauty Is Truth: A History of Symmetry. Basic Books (AZ), 2008. 
‘Stretcher | Features | Nicolas Bourriaud and Karen Moss’. Accessed 9 March 2017.

http://www.stretcher.org/features/nicolas bourriaud and karen moss/.

Todd, Cain S. 'Unmasking the Truth beneath the Beauty: Why the Supposed Aesthetic Judgements Made in Science May Not Be Aesthetic at All'. International Studies in the Philosophy of Science 22, no. 1 (2008): $61-79$.

Weinberg, S. 'Dreams of a Final Theory: The Search for the Fundamental Laws of Nature. Cox \& Wyman, London'. ISBN 0-09-922391-0, 1993.

Zangwill, Nick. 'Aesthetic Judgment'. In The Stanford Encyclopedia of Philosophy, edited by Edward N. Zalta, Fall 2014. Metaphysics Research Lab, Stanford University, 2014. https://plato.stanford.edu/archives/fall2014/entries/aesthetic-judgment/. 